\title{
The Crystal Structure of a Proposed Hinesol Intermediate*
}

\author{
BY J. BORDNER $\dagger$ AND R. E. DICKERSON \\ Gates and Crellin Laboratories of Chemistry, California Institute of Technology, Pasadena, California, U.S.A.
}

(Received 4 August 1969)

The structure of a proposed intermediate of the naturally occurring sesquiterpene hinesol was determined by X-ray analysis. The structure was solved using the heavy-atom technique and refined to an $R$ index of 0.065 for 1739 non-zero reflections. The results of the analysis revealed that the intermediate had a structure incompatible with conversion to hinesol.

\section{Introduction}

A proposed intermediate ( $\mathrm{I} a$ ) in the synthesis of the sesquiterpene hinesol (II) was prepared in the laboratories of Professor J.A. Marshall at Northwestern University (Marshall \& Brady, 1969). Subsequent conversion of the intermediate was not a trivial undertaking, and conventional methods of structure analysis

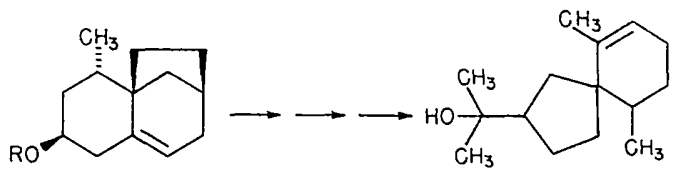

(I)
(II)
(Ia) $\mathrm{R}=\mathrm{H}$

(Ib) $\mathrm{R}=p-\mathrm{BrC}_{6} \mathrm{H}_{4}$. N.C-

* Contribution No. 3710 from the Gates and Crellin Laboratories of Chemistry. This research was supported in part by research grants GM-12121 from the United States Public Health Service and GB-6617X from the National Science Foundation.

$\dot{\dagger}$ Present address: Department of Chemistry, North Carolina State University, Raleigh, North Carolina 27607, U.S.A. were inconclusive. Therefore, an X-ray analysis was undertaken to establish the stereochemistry of the intermediate with certainty.

\section{Experimental}

Suitable crystals of the 4-bromophenylurethane derivative (Ib) were grown from ether/ethyl acetate by slow evaporation. The small plate-like crystals were trimmed to a size of $0.1 \times 0.4 \times 0.4 \mathrm{~mm}$ and surveyed on a precession camera. The survey indicated that the crystals belong to space group $P 2_{1} / c$ (systematic absences: $h 0 l$ with $l$ odd, $0 k 0$ with $k$ odd). The density, measured by flotation, was $1.45 \mathrm{~g} . \mathrm{cm}^{-3}$; the density calculated on the basis of 4 molecules per unit cell was 1.435 g. $\mathrm{cm}^{-3}$.

Sodium chloride calibrated, zero level, precession photographs established the following cell dimensions:

$$
\begin{aligned}
& a=13.555 \pm 0.003 \AA \\
& b=7.595 \pm 0.002
\end{aligned}
$$

One-Ångstrom intensity data (maximum $\sin \theta / \lambda=$ $0.5)$ were collected on a General Electric Datex diffrac-


Fig. 1. Packing diagram. 
tometer using nickel-filtered copper radiation and a scintillation counter. A $\theta-2 \theta$ scan technique was employed, background was counted for 10 seconds at each end of the scan, and the scan rate was $2^{\circ}$ per minute in $2 \theta$. A single check reflection (022) was monitored every
30 reflections and revealed no radiation damage; its variation was well within counter statistics.

The diffractometer output was processed using subprograms of the CRYRM Crystallographic Computer System (Duchamp, 1964). The processing included

Table 1. Observed and calculated structure factors

Within each group are values of $l, F_{o}, F_{c}$. Reflections indicated with an asterisk were assigned zero weight in the final least-squares cycles.

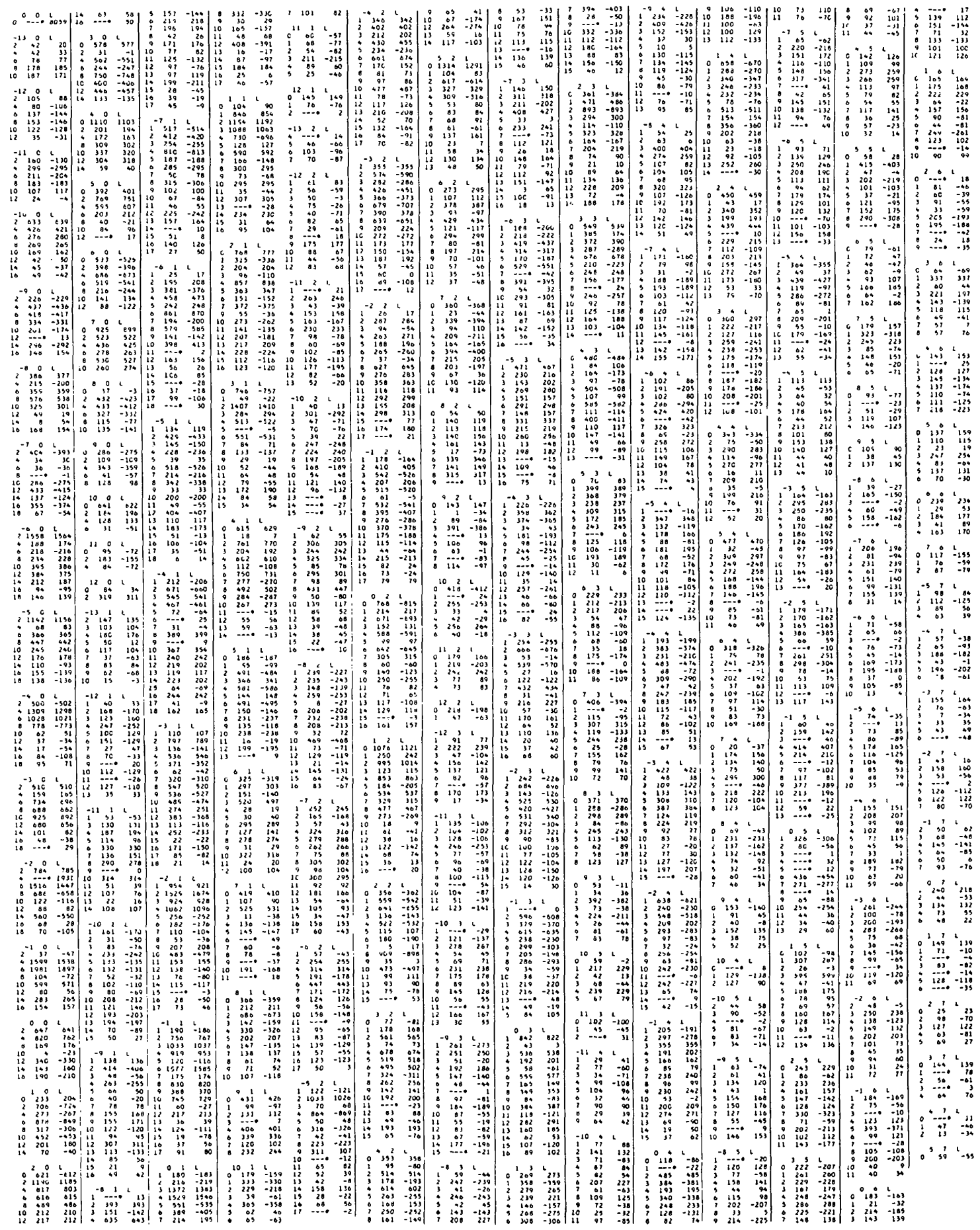


Table 2. The $\mathrm{C}, \mathrm{O}, \mathrm{N}$ and $\mathrm{Br}$ atom parameters and their standard deviations

Values for the bromine atom have been multiplied by $10^{5}$ and those for other atoms by $10^{4}$. The temperature factor is in the form $T=\exp \left[-\left(b_{11} h^{2}+b_{22} k^{2}+b_{33} l^{2}+b_{12} h k+b_{13} h l+b_{23} k l\right)\right]$.

\begin{tabular}{|c|c|c|c|c|c|c|c|c|c|}
\hline & $x$ & $y$ & $z$ & $b_{11}$ & $b_{22}$ & $b_{33}$ & $b_{12}$ & $b_{13}$ & $b_{23}$ \\
\hline $\operatorname{Br}(1)$ & $59314(4)$ & $-22349(8)$ & $47489(4)$ & $821(5)$ & $3210(20)$ & $647(3)$ & $-606(16)$ & $250(6)$ & $-117(13)$ \\
\hline$C(2)$ & 7175 (3) & $-924(2)$ & $5157(2)$ & $65(4)$ & 237 (13) & $28(2)$ & $8(13)$ & $15(5)$ & $10(9)$ \\
\hline$C(3)$ & 7136 (3) & $774(7)$ & $5387(3)$ & $58(4)$ & 281 (15) & $40(2)$ & $34(2)$ & $33(5)$ & $-25(10)$ \\
\hline C(4) & $8040(4)$ & $1745(6)$ & 5659 (3) & $75(4)$ & 195 (13) & $41(2)$ & $46(12)$ & $16(5)$ & $-42(9)$ \\
\hline$C(5)$ & $8985(3)$ & $1019(6)$ & $5701(2)$ & $61(4)$ & $193(12)$ & $29(2)$ & $49(12)$ & $5(5)$ & $0(9)$ \\
\hline$C(6)$ & 9009 (3) & $-704(6)$ & $5480(3)$ & $59(3)$ & $176(12)$ & $42(3)$ & 69 (12) & $15(5)$ & $-1(9)$ \\
\hline$C(7)$ & $8112(4)$ & $-1673(6)$ & $5203(3)$ & 77 (4) & $168(12)$ & $36(2)$ & $18(11)$ & $15(5)$ & $-21(8)$ \\
\hline$N(8)$ & $9940(3)$ & $1923(5)$ & 5990 (2) & $50(3)$ & $179(10)$ & $52(2)$ & $57(9)$ & $-12(4)$ & $-26(8)$ \\
\hline$C(9)$ & $10069(4)$ & $3693(6)$ & 5954 (3) & $76(4)$ & $179(13)$ & $31(2)$ & 48 (13) & $21(5)$ & $-23(9)$ \\
\hline$O(10)$ & $9417(2)$ & $4761(4)$ & $5688(2)$ & $68(3)$ & $198(8)$ & $49(2)$ & $77(8)$ & $11(3)$ & $17(6)$ \\
\hline$O(11)$ & $11109(2)$ & 4013 (4) & $6272(2)$ & $60(2)$ & $168(8)$ & $51(2)$ & $30(8)$ & $-4(3)$ & $-25(6)$ \\
\hline$C(12)$ & $11426(3)$ & $5849(6)$ & $6341(2)$ & $64(4)$ & $140(11)$ & $39(2)$ & 27 (11) & $17(5)$ & $0(9)$ \\
\hline C(13) & $12571(3)$ & $5871(6)$ & 6420 (3) & $63(4)$ & 253 (14) & $42(2)$ & $62(12)$ & $27(5)$ & $-24(10)$ \\
\hline$C(14)$ & $12993(3)$ & $7726(6)$ & $6517(3)$ & $53(3)$ & 237 (13) & $34(2)$ & $34(12)$ & $22(4)$ & $21(9)$ \\
\hline$C(15)$ & $12846(3)$ & $8673(6)$ & $7206(2)$ & $54(4)$ & $170(12)$ & $27(2)$ & $-10(11)$ & $15(5)$ & $11(8)$ \\
\hline$C(16)$ & 11747 (3) & $8428(6)$ & 7241 (2) & $55(3)$ & $169(12)$ & $27(2)$ & $-14(11)$ & $22(4)$ & $2(8)$ \\
\hline$C(17)$ & $11247(3)$ & $6656(6)$ & 7031 (3) & $59(4)$ & $174(12)$ & $37(2)$ & $-5(11)$ & $31(5)$ & $-7(8)$ \\
\hline$C(18)$ & $11312(2)$ & $9630(6)$ & $7550(3)$ & $63(4)$ & $175(12)$ & $38(2)$ & $-15(11)$ & $34(5)$ & $-21(9)$ \\
\hline$C(19)$ & $11858(4)$ & $11271(7)$ & 7919 (3) & $98(4)$ & $221(13)$ & $39(2)$ & $-25(13)$ & $40(6)$ & $-30(9)$ \\
\hline$C(20)$ & $13006(4)$ & $11226(6)$ & $7978(3)$ & $81(4)$ & $210(13)$ & $44(3)$ & $-97(13)$ & $23(6)$ & $-1(10)$ \\
\hline$C(21)$ & $13053(3)$ & $10652(6)$ & $7201(3)$ & $62(3)$ & $230(14)$ & $32(2)$ & $-11(11)$ & $28(5)$ & $37(9)$ \\
\hline$C(22)$ & $13618(3)$ & $8168(7)$ & 8002 (3) & $61(3)$ & $283(15)$ & $37(2)$ & $-1(12)$ & $7(5)$ & $36(10)$ \\
\hline$C(23)$ & $13617(3)$ & $9746(7)$ & $8511(3)$ & $73(4)$ & $313(16)$ & $32(2)$ & $-99(13)$ & $2(5)$ & $25(10)$ \\
\hline$C(24)$ & $14104(4)$ & $7730(7)$ & $6507(3)$ & $78(4)$ & $376(17)$ & $62(3)$ & $97(15)$ & $77(6)$ & $84(11$ \\
\hline
\end{tabular}

corrections for background and for Lorentz and polarization effects. It also included calculation of the $F^{2}$ value and its standard deviation for each of the 1876 reflections (137 reflections had zero intensity). The standard deviations were assigned on the basis of the following equation:

$$
\sigma^{2}(I)=S+\left(B_{1}+B_{2}\right) \alpha^{2}+(d S)^{2} .
$$

Here, $S$ is the scan count, $B_{1}$ and $B_{2}$ are the background counts, $d$ is an empirical constant equal to 0.02 , and $\alpha=n / 2 m t$ where $n=$ scan range, $m=$ scanning speed and $t=$ time for background count in seconds. Finally, the data were placed on an absolute scale by means of Wilson (1942) statistics. No corrections for absorption were made.

\section{Determination and refinement of the structure}

The trial structure was derived by the usual Patterson and Fourier techniques in three dimensions. Fullmatrix least-squares refinement of coordinates, isotropic temperature factors (bromine anisotropic), and scale factor reduced the $R$ index to $11 \cdot 3 \%$. A difference Fourier synthesis indicated no misplaced or missing $\mathrm{Br}, \mathrm{C}, \mathrm{N}$, or $\mathrm{O}$ atoms. The difference synthesis was also utilized to locate the hydrogen atoms of the methyl group; the remaining hydrogen atoms were positioned from geometric considerations. The addition of the hydrogen atoms to the structure factor calculation and the application of anisotropic temperature factors to the refinement reduced the $R$ index to its final value of $6.5 \%$. The quantity minimized was $\sum w\left(F_{o}^{2}-F_{c}^{2}\right)^{2}$; no shift in the final cycle was greater than $0.3 \sigma$.
The observed and calculated structure factors for the refined structure are listed in Table 1.

\section{Crystallography}

\section{Discussion}

The structure obtained was plotted stereographically using the ORTEP program of Johnson (1965). The final refined atomic parameters and their standard deviations are presented in Table 2 . The bond lengths

\section{Table 3. Bond distances}

The numbering scheme represents a convenient crystallographic one and is not the correct organic nomenclature. Estimated standard deviations are about $0 \cdot 01 \AA$.<smiles>C[C@@H]1CC(OC(=O)Nc2ccc(Br)cc2)CC2=CCC3CCC21C3</smiles>

$\begin{array}{llll}\operatorname{Br}(1)-C(2) & 1.89 \AA & C(13)-C(14) & 1.51 \AA \\ C(2)-C(3) & 1.36 & C(14)-C(15) & 1.53 \\ C(2)-C(7) & 1.37 & C(14)-C(24) & 1.51 \\ C(3)-C(4) & 1.38 & C(15)-C(16) & 1.52 \\ C(4)-C(5) & 1.38 & C(15)-C(21) & 1.53 \\ C(5)-C(6) & 1.38 & C(15)-C(22) & 1.55 \\ C(5)-N(8) & 1.41 & C(16)-C(17) & 1.50 \\ C(6)-C(7) & 1.37 & C(16)-C(18) & 1.31 \\ N(8)-C(9) & 1.36 & C(18)-C(19) & 1.50 \\ C(9)-O(10) & 1.18 & C(19)-C(20) & 1.53 \\ C(9)-O(11) & 1.36 & C(20)-C(21) & 1.52 \\ O(11)-C(12) & 1.45 & C(20)-C(23) & 1.54 \\ C(12)-C(13) & 1.51 & C(22)-C(23) & 1.52 \\ C(12)-C(17) & 1.50 & & \end{array}$


Table 4. Bond angles

Estimated standard deviations are about $0.5^{\circ}$.

$\begin{array}{ll}C(3)-C(2)-B r(1) & 120^{\circ} \\ C(7)-C(2)-B r(1) & 120 \\ C(3)-C(2)-C(7) & 120 \\ C(4)-C(3)-C(2) & 120 \\ C(5)-C(4)-C(3) & 121 \\ C(6)-C(5)-C(4) & 119 \\ C(7)-C(6)-C(5) & 121 \\ C(2)-C(7)-C(6) & 120 \\ N(8)-C(5)-C(4) & 124 \\ N(8)-C(5)-C(6) & 118 \\ C(9)-N(8)-C(5) & 125 \\ O(10)-C(9)-N(8) & 127 \\ O(11)-C(9)-N(8) & 107 \\ O(10)-C(9)-O(11) & 126\end{array}$

$\begin{array}{ll}C(12)-O(11)-C(9) & 116^{\circ} \\ C(13)-C(12)-O(11) & 106 \\ C(17)-C(12)-O(11) & 110 \\ C(13)-C(12)-C(17) & 111 \\ C(14)-C(13)-C(12) & 111 \\ C(15)-C(14)-C(13) & 113 \\ C(16)-C(15)-C(14) & 112 \\ C(17)-C(16)-C(15) & 118 \\ C(12)-C(17)-C(16) & 114 \\ C(24)-C(14)-C(13) & 110 \\ C(24)-C(14)-C(15) & 114 \\ C(18)-C(16)-C(15) & 121 \\ C(18)-C(16)-C(17) & 120\end{array}$

$\begin{array}{ll}C(19)-C(18)-C(16) & 123^{\circ} \\ C(20)-C(19)-C(18) & 111 \\ C(21)-C(20)-C(19) & 107 \\ C(15)-C(21)-C(20) & 102 \\ C(21)-C(15)-C(16) & 108 \\ C(21)-C(15)-C(14) & 113 \\ C(22)-C(15)-C(16) & 107 \\ C(22)-C(15)-C(14) & 116 \\ C(22)-C(15)-C(21) & 100 \\ C(23)-C(22)-C(15) & 105 \\ C(20)-C(23)-C(22) & 107 \\ C(23)-C(20)-C(19) & 113 \\ C(23)-C(20)-C(21) & 102\end{array}$

and angles are given in Tables 3 and 4 . The standard deviations in the coordinates, derived from the residuals and the diagonal elements of the inverse matrix of the final least-squares cycle, correspond to positional uncertainties of about $0.001 \AA$ for the bromine atom and about $0.006 \AA$ for the carbon, nitrogen, and oxygen atoms. The uncertainties for the $\mathrm{Br}, \mathrm{C}, \mathrm{N}, \mathrm{O}$ bonds are about $0.01 \AA$. Uncertainties in the bond angles involving the $\mathrm{C}, \mathrm{O}, \mathrm{N}$ and $\mathrm{Br}$ atoms are approximately $0.5^{\circ}$. Since the hydrogen positions were not refined, no error estimates have been made for distances and angles involving these atoms. The coordinates of the hydrogen atoms are listed in Table 5 .

A stereoscopic view showing the packing of the molecules is given in Fig. 2. There are no short contacts between molecules; the shortest major-atom-tohydrogen intermolecular distance is $2.44 \AA$, between $\mathrm{H}(47)$ of the base molecule and $\mathrm{O}(10)$ of the molecule at $x, y-1, z$, while the shortest intermolecular $\mathrm{H} \ldots \mathrm{H}$ distance is $2 \cdot 22 \AA$, between $\mathrm{H}(37)$ in the base molecule
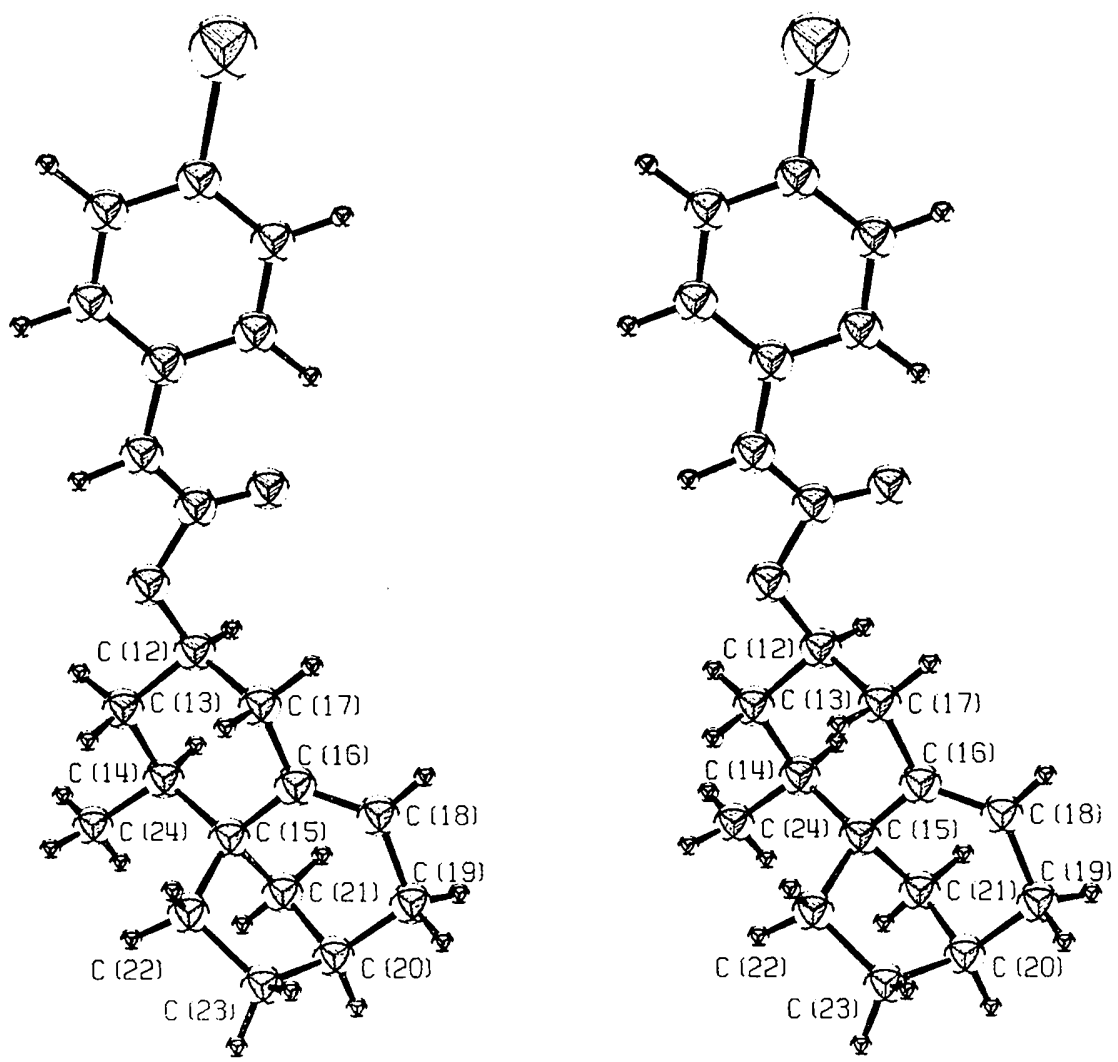

Fig.2. Stereoplot of the molecule viewed down the $c$ axis. 
and $H(45)$ of the molecule in equivalent position $2-x$, $\frac{1}{2}+y, \frac{3}{2}-z$.

Table 5. Hydrogen atom coordinates

Values have been multiplied by $10^{4}$. The isotropic temperature factor for all hydrogen atoms equals $4 \cdot 5$.

$\begin{array}{lccrc} & \text { Bonded to } & x & y & z \\ \mathrm{H}(25) & \mathrm{C}(24) & 14541 & 6999 & 6848 \\ \mathrm{H}(26) & \mathrm{C}(24) & 14360 & 9061 & 6437 \\ \mathrm{H}(27) & \mathrm{C}(24) & 14207 & 7435 & 6058 \\ \mathrm{H}(28) & \mathrm{C}(12) & 11083 & 6719 & 5888 \\ \mathrm{H}(29) & \mathrm{C}(13) & 12710 & 5274 & 5974 \\ \mathrm{H}(30) & \mathrm{C}(13) & 12979 & 5173 & 6907 \\ \mathrm{H}(31) & \mathrm{C}(14) & 12585 & 8381 & 6028 \\ \mathrm{H}(32) & \mathrm{C}(17) & 11560 & 5997 & 7486 \\ \mathrm{H}(33) & \mathrm{C}(17) & 10476 & 6724 & 6951 \\ \mathrm{H}(34) & \mathrm{C}(22) & 14357 & 7930 & 7994 \\ \mathrm{H}(35) & \mathrm{C}(22) & 13386 & 7062 & 8217 \\ \mathrm{H}(36) & \mathrm{C}(23) & 14361 & 10139 & 8811 \\ \mathrm{H}(37) & \mathrm{C}(23) & 13265 & 9449 & 8907 \\ \mathrm{H}(38) & \mathrm{C}(20) & 13353 & 12442 & 8121 \\ \mathrm{H}(39) & \mathrm{C}(21) & 13777 & 10920 & 7135 \\ \mathrm{H}(40) & \mathrm{C}(21) & 12522 & 11286 & 6757 \\ \mathrm{H}(41) & \mathrm{C}(19) & 11513 & 12379 & 7620 \\ \mathrm{H}(42) & \mathrm{C}(19) & 11801 & 11426 & 8461 \\ \mathrm{H}(43) & \mathrm{C}(18) & 10555 & 9841 & 7529\end{array}$

Table 5 (cont.)

$\begin{array}{lcrrr} & \text { Bonded to } & x & y & z \\ \mathrm{H}(44) & \mathrm{C}(3) & 6422 & 1308 & 5347 \\ \mathrm{H}(45) & \mathrm{C}(4) & 8002 & 3054 & 5803 \\ \mathrm{H}(46) & \mathrm{C}(6) & 9736 & -1256 & 5519 \\ \mathrm{H}(47) & \mathrm{C}(7) & 8157 & -2985 & 5034 \\ \mathrm{H}(48) & \mathrm{N}(8) & 10583 & 1169 & 6254\end{array}$

\section{Chemistry}

The chemical results of the analyses are illustrated in Fig. 2. It can be seen that the intermediate examined would not be suitable for conversion to the desired sesquiterpene since it is the syn isomer rather than the desired anti isomer.

\section{References}

Duchamp, D. J. (1964). Proc. Amer. Cryst. Assoc. Meeting, Bozeman, Montana, paper B-14, p. 29.

JoHNSON, C. K. (1965). ORTEP. Report ORNL-3794, Oak Ridge National Laboratories, Oak Ridge, Tennessee.

Marshall, J. A. \& Brady, S. F. (1969). Tetrahedron Letters, (18), p. 1387.

Wilson, A. J. C. (1942). Nature, Lond. 150, 152.

Acta Cryst. (1970). B26, 1622

\title{
The Structure of Tricycloquinazoline
}

\author{
By Margaret L. Bailey,* J. P. M. Bailey $\dagger$ and C. A. Coulson \\ Mathematical Institute, Oxford, England
}

(Recieved 1 December 1969)

\begin{abstract}
A molecular-orbital study of the $\pi$ electrons in tricycloquinazoline has been used to predict atomic charges and bond orders. Four different molecular-orbital approximations all lead to results in good qualitative agreement with the recent experimental results of Iball \& Motherwell. The outer part of the molecule should show aromatic character, but the central part should not. An approximate valence bond treatment gives substantially similar results. Quantitatively the accuracy of the predicted C-N bond lengths is considerably worse than that of the $\mathrm{C}-\mathrm{C}$ bond lengths. The largest disagreement with experiment lies in the three central $\mathrm{N}-\mathrm{C}$ bonds, which appear to be $0.03 \AA$ longer than predicted.
\end{abstract}

\section{Introduction}

The crystal structure of the planar carcinogenic molecule tricycloquinazoline (TCQ, see Fig. 1) has recently been reported by Iball \& Motherwell (1969). The structural interest in this molecule lies in the fact that although the outer three rings are highly benzenoid in character, the inner group of three rings (tetra-azaperinaphthenyl) show marked differences in bond length, so that they may be classed as polyolefinic, and not

\footnotetext{
* Present address: Chemistry Department, Victoria University, Wellington, New Zealand.

$\dagger$ Present address: Chemistry Division, D.S.I.R., Wellington, New Zealand.
}

aromatic. This latter situation is not entirely unexpected; for, if the three equivalent nitrogen atoms were replaced by carbon atoms, the presence of the outer benzenoid rings would reduce the $D_{3 h}$ symmetry then possessed by the perinaphthenyl region to $C_{3 h}$ symmetry, and thus lead to significantly decreased aromaticity in the central region, along the lines of an argument due to Dewar \& Trinajstic (1969).

This molecule is also interesting because in addition to seven chemically distinct $\mathrm{C}-\mathrm{C}$ bonds there are three distinct $\mathrm{C}-\mathrm{N}$ bonds; this permits a useful comparison between theory and experiment.

We have therefore thought it worth while to make a theoretical study of TCQ, using one or more variants of the molecular-orbital (MO) theory. The central $\mathrm{N}$ 